\title{
What do central venous catheter-associated bloodstream infections have to do with bundles?
}

\author{
BL Johnston MD', JM Conly MD²
}

$\mathrm{I}_{\mathrm{N}}^{\mathrm{n}}$

nterest in the patient safety agenda continues to grow in North America. In the United States (US), the Institute for Healthcare Improvement (IHI) has begun a campaign to make health care safer and more effective by encouraging hospitals to implement interventions they believe can avoid 100,000 deaths between January 2005 and July 2006 (1). The IHI, a not-for-profit organization founded in 1991, promotes the improvement of health by advancing the quality and value of health care (2). Three of the six areas for action chosen by the IHI for their '100,000 Lives Campaign' relate to prevention of nosocomial infections: central line infections, surgical site infections and ventilator-associated pneumonia. In Canada, a grassroots patient safety campaign modelled after the IHI's '100,000 Lives Campaign' has formed (3). This 'Safer Healthcare Now!' campaign focuses on the same six strategies chosen for the ' 100,000 Lives Campaign'. Across the country, hospitals are being invited to join the 'Safer Healthcare Now!' campaign.

In a previous issue of the Journal, we reviewed the relationship between hospital-acquired infection and patient safety (4). Nosocomial infections are the most common complications affecting hospitalized patients, with $5 \%$ to $10 \%$ of patients admitted to US acute care hospitals acquiring one or more infections (5). In absolute numbers, this translates into approximately two million patients in the US developing a hospital-acquired infection every year, with an estimated 90,000 deaths and a US $\$ 4.5$ to US $\$ 5.7$ billion cost of care (6). These findings are supported by other studies. A multicentre point prevalence study conducted in Italian hospitals in October 2001 (7) found that 163 of 2165 patients (7.5\%) had 179 nosocomial infections. A similar point prevalence study, conducted in February 2002 by hospitals participating in the Canadian Nosocomial Infection Surveillance Program, identified 681 of 6747 patients (10.1\%) with 746 nosocomial infections (D Gravel, personal communication). At greatest risk for infection and poor outcome are patients in critical care units (7-11).

While bloodstream infections (BSIs) are not the most common of nosocomial infections, they have long been recognized as having a significant impact on outcome and costs, and may be among the most preventable of the nosocomial infections. Nosocomial bacteremias are divided into primary and secondary types. A primary bloodstream infection refers to a bacteremia or fungemia for which there is no documented source, and includes intravenous or arterial line infections. A secondary bloodstream infection is one that develops from a documented infection with the same organism at another body site. Most nosocomial bacteremias are primary in nature (12), and central venous catheters (CVCs) are the most frequent cause of nosocomial BSI (13). Therefore, it is not surprising that both the '100,000 Lives' and 'Safer Healthcare Now!' campaigns have focused on central line infection prevention as one of their strategies.

Information specifically related to BSI rates is available from several sources. The National Nosocomial Infections Surveillance System has been collecting data from selected US hospitals since 1970 . Over the past 13 years, investigators from this tracking system have focused on nosocomial infections in surgical patients and in patients located in high-risk nurseries and adult and pediatric intensive care units (ICUs). A National Nosocomial Infections Surveillance System summary in October 2004 reported CVC-associated BSI rates ranging from $2.7 / 1000$ to $7.4 / 1000$ central-line-days in ICUs and $3.5 / 1000$ to $9.1 / 1000$ central-line-days in high-risk nurseries (14). Another nationwide database that provides information on nosocomial infections is the Surveillance and Control of Pathogens of Epidemiologic Importance (SCOPE) project, which includes 49 hospitals in 32 states in the US. Between March 1995 and September 2002, this project reported 24,279 BSIs for a rate of $60 / 10,000$ hospital admissions, with no trend over time observed (15). Approximately one-half of the BSIs occurred in the ICU and $15 \%$ were identified in pediatric patients (15). In a study of patients admitted to the medical and surgical ICUs of a nonteaching hospital in Missouri, USA, investigators determined that $1 \%$ of all patients and $4 \%$ of patients with a CVC developed a primary BSI, for a rate of 4/1000 catheter-days (16). This suggests that the risk for nosocomial infection is similar in nonteaching community and

\footnotetext{
${ }^{1}$ Queen Elizabeth II Health Sciences Centre and Dalhousie University, Halifax, Nova Scotia; ${ }^{2}$ Departments of Pathology and Laboratory

Medicine, Medicine, and Microbiology and Infectious Diseases, Centre for Antimicrobial Resistance, University of Calgary, Calgary, Alberta Correspondence and reprints: Dr BL Johnston, Queen Elizabeth II Health Sciences Centre, 1278 Tower Road, Halifax, Nova Scotia B3H 2 Y9.

Telephone 902-473-5553, fax 902-473-7394, e-mail ljohnsto@dal.ca

Received and accepted for publication July 18, 2005
} 
tertiary-care teaching hospitals. Comparable BSI rates have been reported from Finnish (0.8/1000 patient-days) (17) and Greek (3.6/1000 admissions) (18) studies.

The spectrum of organisms isolated from patients with nosocomial BSIs tends to be consistent from one study to another. The most common pathogens are Gram-positive organisms: coagulase-negative staphylococci, Staphylococcus aureus and enterococci $(15-18)$. While the relative frequencies of pathogens have remained fairly stable over the past decade, the continued increase in antimicrobial-resistant strains, especially methicillin-resistant $S$ aureus, is of concern $(14,15)$.

Crude mortality rates for nosocomial BSIs have ranged from $16 \%$ to $53 \%$, varying with organism and patient acuity of illness $(12,15,17,19,20)$. Studies have generally identified excess attributable mortality due to the presence of a nosocomial BSI. Independent of mortality outcomes, nosocomial BSIs are associated with excess hospital and/or ICU length of stay $(16,19,21)$, as well as excess costs (19).

The vast majority of studies examining CVC-related infections have been in the hospital setting. However, recent studies have demonstrated that community-acquired bacteremia is often device-related. Over a four-year study period (1994 to 1998) in Seattle, Washington, USA, intravascular catheters were implicated in $20.4 \%$ of community-acquired BSIs (22). The crude mortality rate for intravascular catheter-related BSI was $7.1 \%$, which did not represent an independent risk factor for death (22). In 1996, Steinberg et al (23) reported a 22\% increase in community-acquired $S$ aureus bacteremias related to intravascular catheters between 1980 and 1993. A study that distinguished between community-acquired, health careassociated (but not strictly hospital-acquired) and nosocomial BSIs found that there were as many health care-associated infections (37\%) as there were nosocomial infections (35\%) (24). Patients with health care-associated BSIs and nosocomial BSIs had similar frequencies of CVC-related infections, and $20 \%$ of these infections were due to methicillin-resistant $S$ aureus (24). In-hospital mortality was higher for the nosocomial BSIs, but long-term survival was the same for health careassociated BSIs and nosocomial BSIs in this cohort (24). It is to be expected that as more health care is delivered outside of the hospital, there will be an increase in the number of community-acquired (but health care-associated) infections, and that preventive efforts should be applied in that setting as well.

It has already been identified that intravascular devices are responsible for most health care-associated (including nosocomial) BSIs. A study of 17 teaching and 56 nonteaching acute hospitals in England between 1997 and 2001 found that devices were responsible for $52.4 \%$ and $43.3 \%$ of nosocomial BSIs, respectively, and that central lines were the most common source (25). This study was also able to identify high-risk populations for targeted surveillance and prevention efforts. In teaching hospitals, high-risk populations were in ICUs, hematology, special care nurseries, nephrology, and oncology, where central lines accounted for $89 \%$ of device-related bacteremias (25). This suggests, therefore, that prevention efforts in teaching should be directed at line management in specific patient populations. In nonteaching hospitals, the above-noted populations accounted for a small proportion of bacteremias, suggesting that efforts should be focused elsewhere in those types of facilities (25). Other factors have been identified that influence nosocomial BSI rates. Among these are factors related to health care worker staffing and expertise. Two separate studies showed that reduced nurse-to-patient ratios in the ICU were associated with increased nosocomial BSI rates $(26,27)$. Furthermore, another study found that, in addition to the staffing ratio, the training of nursing personnel in a surgical ICU impacts on BSI risk (28).

A number of strategies have been identified to reduce the incidence of CVC-associated BSIs. These strategies have come from observational studies that identify modifiable risks for infection and from randomized, controlled trials examining specific interventions. Observational studies have reported that the risk of BSI or catheter colonization is high for lines inserted into the internal jugular and femoral veins (29-31). Based on this finding, the subclavian site is preferred for CVC insertion. Chlorhexidine is superior to povidone-iodine and alcohol when cleansing the site before central line insertion (32). More than 10 years ago, Raad et al (33) demonstrated that maximal sterile barrier precautions (sterile gloves, longsleeved sterile gown, mask, cap and large, sterile sheet drape) reduce the risk of CVC-associated BSI. A number of studies have examined the benefit of antimicrobial-coated or -impregnated catheters (29,34-36). Studies with these devices showed reduced BSI rates. However, there are several considerations when applying these results in practice. In some studies, the BSI rate was quite high in control subjects, suggesting that these devices may have their greatest use in centres with high BSI rates despite the implementation of other proven manoeuvres. Additionally, the benefit of these devices is with catheters intended for relatively short-term use (less than 14 to 28 days, depending on device). Several other recommendations related to the management of central venous and arterial catheters have been made by Mermel (29) and the Centers for Disease Control and Prevention (37). In terms of catheter maintenance, these recommendations include low-dose heparin for patients with short-term CVCs; adequate nurse-topatient ratios in ICUs; continuing quality improvement programs to improve compliance with catheter care guidelines; disinfection of catheter hubs and sampling ports before accessing; specialized nursing teams caring for patients with catheter usage for total parenteral nutrition; and removing catheters as soon as possible after intended use. Either transparent or gauze dressings are acceptable, and the routine replacement of CVCs is not indicated to prevent infection $(29,37)$. The IHI has incorporated five elements into its central line bundle: hand hygiene; maximal barrier precautions; chlorhexidine skin antisepsis; optimal catheter site selection with subclavian vein as the preferred site for nontunneled catheters; and daily review of line necessity with prompt removal of unnecessary lines (1).

One would think it simple enough to implement the proven and agreed upon preventive strategies; however, there is literature to suggest that this is not necessarily the case. A single-day prevalence survey of CVC use among adult inpatients at six US medical centres found that the jugular site was used in 33\% of ICU patients with central lines (38). In another US study examining processes of care (39), it was noted that the jugular was the insertion site in $43.6 \%$ of ICU patients, and that a large drape and sterile gown were used in $58.1 \%$ and $76.8 \%$ of CVC insertions, respectively. Alonso-Echanove et al (40) identified care by a float nurse for more than $60 \%$ of CVC-days as an independent predictor of CVC-related BSI; in this ICU study, the range of proportion of float nurse-days was $0 \%$ to $25 \%$ and the median nurse-to-patient ratio was 0.5 . An examination of factors influencing internists' use of maximal 
barriers and proper skin antisepsis for central catheter insertion noted that only $28.2 \%$ of respondents were compliant with all components of maximal barriers (41). The key reasons for nonadherence included limited access to chlorhexidine and the fact that the internists did not believe in the effectiveness of maximal barrier precautions (41). Factors not found to influence compliance were experience with CVC insertion, specialty, practising in an academic medical centre, and awareness of the guidelines. Although these findings might have been influenced by the low response rate to the survey (52.9\%), our collective experience suggests that these findings reflect the truth. While similar studies have not been performed in Canada, the observation that there is significant variation in CVCrelated infection risk among Canadian neonatal ICUs (after controlling for patient characteristics and illness severity at admission) suggests the potential for variation of practices that influences BSI rates (42).

Ambitious goals have been set out by the '100,000 Lives' and 'Safer Healthcare Now!' campaigns. However, prevention of primary BSIs is an important patient safety goal. Studies suggest that these goals can be achieved through focused programs concentrating on surveillance, education, implementation of proven practices and feedback to providers $(43,44)$. Front-line health care workers need to be prepared to effect change. Administrators must provide the resources required to implement and monitor these changes, and then measure the outcomes.

\section{REFERENCES}

1. 100K Lives Campaign. <www.ihi.org/IHI/Programs/Campaign> (Version current at July 19, 2005).

2. Institute for Healthcare Improvement. <http://www.ihi.org/ihi/about> (Version current at July 19, 2005).

3. Safer Healthcare Now! - frequently asked questions. $<$ www.saferhealthcarenow.ca/en/faq.aspx > (Version current at July 19, 2005).

4. Johnston BL, Conly JM. Patient safety: What does it all mean? Can J Infect Dis 2004;15:75-7.

5. Burke JP. Infection control - a problem for patient safety. N Engl J Med 2003;348:651-6.

6. Stone PW, Larson E, Kawar LN. A systematic audit of economic evidence linking nosocomial infections and infection control interventions: 1990-2000. Am J Infect Control 2002;30:145-52.

7. Nicastri E, Petrosillo N, Martini L, et al; INF-NOS Study Group. Prevalence of nosocomial infections in 15 Italian hospitals: First point prevalance study for the INF-NOS project. Infection 2003;31(Suppl 2):10-5.

8. Fagon JY, Novara A, Stephan F, Girou E, Safar M. Mortality attributable to nosocomial infections in the ICU. Infect Control Hosp Epidemiol 1994;15:428-34.

9. Craven DE, Kunches LM, Lichtenberg DA, et al. Nosocomial infection and fatality in medical and surgical intensive care unit patients. Arch Intern Med 1998;148:1161-8.

10. Bueno-Cavanillas A, Delgado-Rodriguez M, López-Luque A, Schaffino-Cano S, Gálvez-Vargas R. Influence of nosocomial infection on mortality rate in an intensive care unit. Crit Care Med 1994;22:55-60.

11. Jarvis WR. Selected aspects of the socioeconomic impact of nosocomial infections: Morbidity, mortality, cost, and prevention. Infect Control Hosp Epidemiol 1996;17:552-7.

12. Pittet D, Wenzel RP. Nosocomial bloodstream infections. Secular trends in rates, mortality, and contribution to total hospital deaths. Arch Intern Med 1995;155:1177-84.

13. Safdar N, Fine JP, Maki DG. Meta-analysis: Methods for diagnosing intravascular device-related bloodstream infection. Ann Intern Med 2005;142:451-66.

14. National Nosocomial Infections Surveillance System. National Nosocomial Infections Surveillance (NNIS) System Report, data summary from January 1992 through June 2004, issued October 2004. Am J Infect Control 2004;32:470-85.
15. Wisplinghoff H, Bischoff T, Tallent SM, Seifert H, Wenzel RP, Edmond MB. Nosocomial bloodstream infections in US hospitals: Analysis of 24,179 cases from a prospective nationwide surveillance study. Clin Infect Dis 2004;39:309-17.

16. Warren DK, Zack JE, Elward AM, Cox MJ, Fraser VJ. Nosocomial primary bloodstream infections in intensive care unit patients in a nonteaching community medical center: A 21 -month prospective study. Clin Infect Dis 2001;33:1329-35.

17. Lyytikainen O, Lumio J, Sarkkinen H, Kolho E, Kostiala A, Ruutu P; Hospital Infection Surveillance Team. Nosocomial bloodstream infections in Finnish hospitals during 1999-2000. Clin Infect Dis 2002;35:e14-9.

18. Arvanitidou M, Katikaridou E, Douboyas J, Tsakris A. Epidemiological characteristics of nosocomial bacteraemias among ICU and non-ICU patients in a tertiary-care hospital in Greece. J Hosp Infect 2005;59:70-2.

19. Pittet D, Tarara D, Wenzel RP. Nosocomial bloodstream infection in critically ill patients. Excess length of stay, extra costs, and attributable mortality. JAMA 1994;271:1598-601.

20. Garrouste-Orgeas M, Chevret S, Mainardi JL, Timsit JF, Misset B, Carlet J. A one-year prospective study of nosocomial bacteraemia in ICU and non-ICU patients and its impact on patient outcome. J Hosp Infect 2000;44:206-13.

21. Renaud B, Brun-Buisson C; ICU-Bacteremia Study Group. Outcomes of primary and catheter-related bacteremia. A cohort and case-control study in critically ill patients. Am J Respir Crit Care Med 2001;163:1584-90.

22. Lark RL, Saint S, Chenoweth C, Zemencuk JK, Lipsky BA, Plorde JJ. Four-year prospective evaluation of community-acquired bacteremia: Epidemiology, microbiology, and patient outcome. Diagn Microbiol Infect Dis 2001;41:15-22.

23. Steinberg JP, Clark CC, Hackman BO. Nosocomial and community-acquired Staphylococcus aureus bacteremias from 1980 to 1993: Impact of intravascular devices and methicillin resistance. Clin Infect Dis 1996;23:255-9.

24. Friedman ND, Kaye KS, Stout JE, et al. Health care-associated bloodstream infections in adults: A reason to change the accepted definition of community-acquired infections. Ann Intern Med 2002;137:791-7.

25. Coello R, Charlett A, Ward V, et al. Device-related sources of bacteraemia in English hospitals - opportunities for the prevention of hospital-acquired bacteraemia. J Hosp Infect 2003;53:46-57.

26. Fridkin SK, Pear SM, Williamson TH, Galgiani JN, Jarvis WR. The role of understaffing in central venous catheter-associated bloodstream infections. Infect Control Hosp Epidemiol 1996;17:150-8.

27. Archibald LK, Manning ML, Bell LM, Banerjee S, Jarvis WR. Patient density, nurse-to-patient ratio and nosocomial infection risk in a pediatric cardiac intensive care unit. Pediatr Infect Dis J 1997;16:1045-8.

28. Robert J, Fridkin SK, Blumberg HM, et al. The influence of the composition of the nursing staff on primary bloodstream infection rates in a surgical intensive care unit. Infect Control Hosp Epidemiol 2000;21:12-7.

29. Mermel LA. Prevention of intravascular catheter-related infections. Ann Intern Med 2000;132:391-402.

30. Richet H, Hubert B, Nitemberg G, et al. Prospective multicenter study of vascular-catheter-related complications and risk factors for positive central-catheter cultures in intensive care unit patients. J Clin Microbiol 1990;28:2520-5.

31. Goetz AM, Wagener MM, Miller JM, Muder RR. Risk of infection due to central venous catheters: Effect of site of placement and catheter type. Infect Control Hosp Epidemiol 1998;19:842-5.

32. Chaiyakunapruk N, Veenstra DL, Lipsky BA, Saint S. Chlorhexidine compared with povidone-iodine solution for vascular catheter-site care: A meta-analysis. Ann Intern Med 2002;136:792-801.

33. Raad II, Hohn DC, Gilbreath BJ, et al. Prevention of central venous catheter-related infections by using maximal sterile barrier precautions during insertion. Infect Control Hosp Epidemiol 1994;15:231-8.

34. Hanna HA, Raad II, Hackett B, et al; M.D. Anderson Catheter Study Group. Antibiotic-impregnated catheters associated with significant decrease in nosocomial and multidrug-resistant bacteremias in critically ill patients. Chest 2003;124:1030-8.

35. Maki DG, Stolz SM, Wheeler S, Mermel LA. Prevention of central venous catheter-related bloodstream infection by use of an 
antiseptic-impregnated catheter. A randomized, controlled trial. Ann Intern Med 1997;127:257-66.

36. Raad I, Darouiche R, Dupuis J, et al. Central venous catheters coated with minocycline and rifampin for the prevention of catheter-related colonization and bloodstream infections. A randomized, double-blind trial. The Texas Medical Center Catheter Study Group. Ann Intern Med 1997;127:267-74.

37. O'Grady NP, Alexander M, Dellinger EP, et al. Guidelines for the prevention of intravascular catheter-related infections. Centers for Disease Control and Prevention. MMWR Recomm Rep 2002;51(RR-10):1-29.

38. Climo M, Diekema D, Warren DK, et al. Prevalence of the use of central venous access devices within and outside of the intensive care unit: Results of a survey among hospitals in the prevention epicenter program of the Centers for Disease Control and Prevention. Infect Control Hosp Epidemiol 2003;24:942-5.

39. Braun BI, Kritchevsky SB, Wong ES, et al; Evaluation of Processes and Indicators in Infection Control Study Group. Preventing central venous catheter-associated primary bloodstream infections: Characteristics of practices among hospitals participating in the
Evaluation of Processes and Indicators in Infection Control (EPIC) study. Infect Control Hosp Epidemiol 2003;24:926-35.

40. Alonso-Echanove J, Edwards JR, Richards MJ, et al. Effect of nurse staffing and antimicrobial-impregnated central venous catheters on the risk for bloodstream infections in intensive care units. Infect Control Hosp Epidemiol 2003;24:916-25.

41. Rubinson L, Wu AW, Haponik EF, Diette GB. Why is it that internists do not follow guidelines for preventing intravascular catheter infections? Infect Control Hosp Epidemiol 2005;26:525-33.

42. Chien LY, Macnab Y, Aziz K, Andrews W, McMillan DD, Lee SK; Canadian Neonatal Network. Variations in central venous catheter-related infection risks among Canadian neonatal intensive care units. Pediatr Infect Dis J 2002;21:505-11.

43. Warren DK, Zack JE, Cox MJ, Cohen MM, Fraser VJ.

An educational intervention to prevent catheter-associated bloodstream infections in a nonteaching, community medical center. Crit Care Med 2003;31:1959-63.

44. Harbarth S, Sax H, Gastmeier P. The preventable proportion of nosocomial infections: An overview of published reports. J Hosp Infect 2003;54:258-66. 


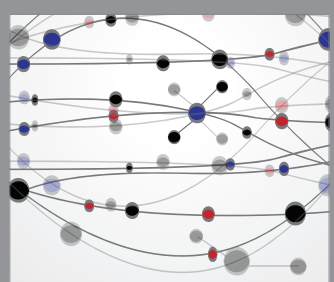

The Scientific World Journal
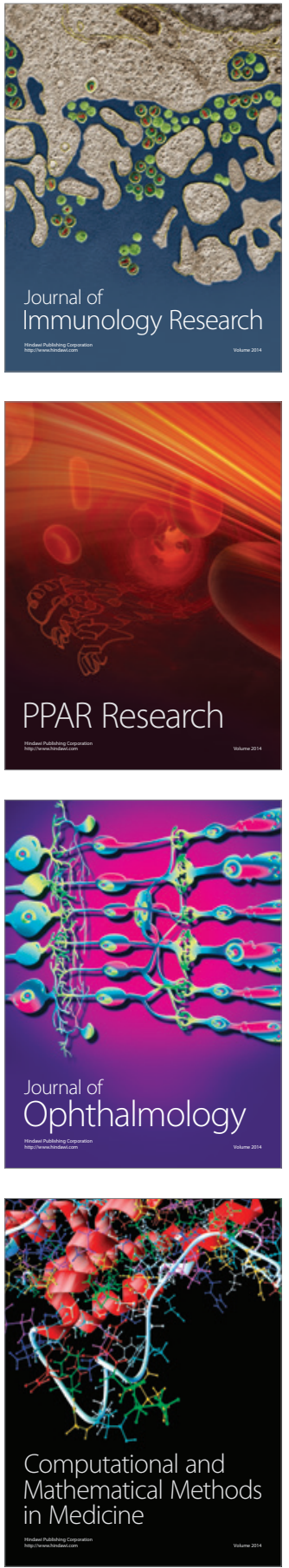

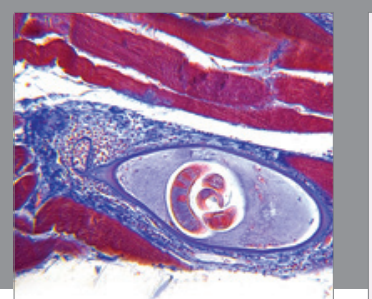

Gastroenterology Research and Practice

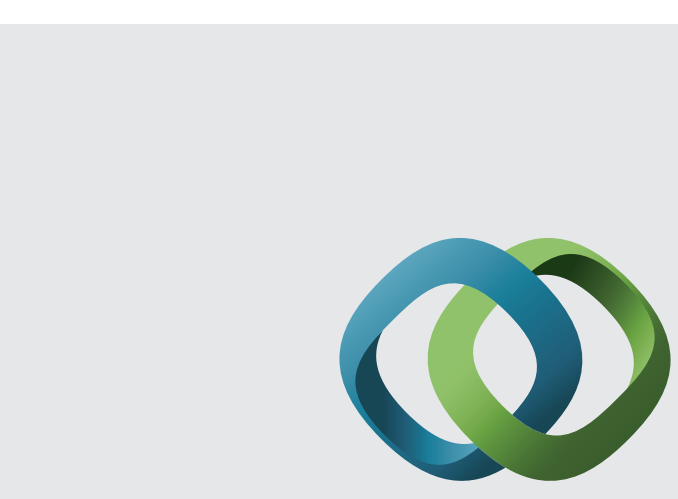

\section{Hindawi}

Submit your manuscripts at

http://www.hindawi.com
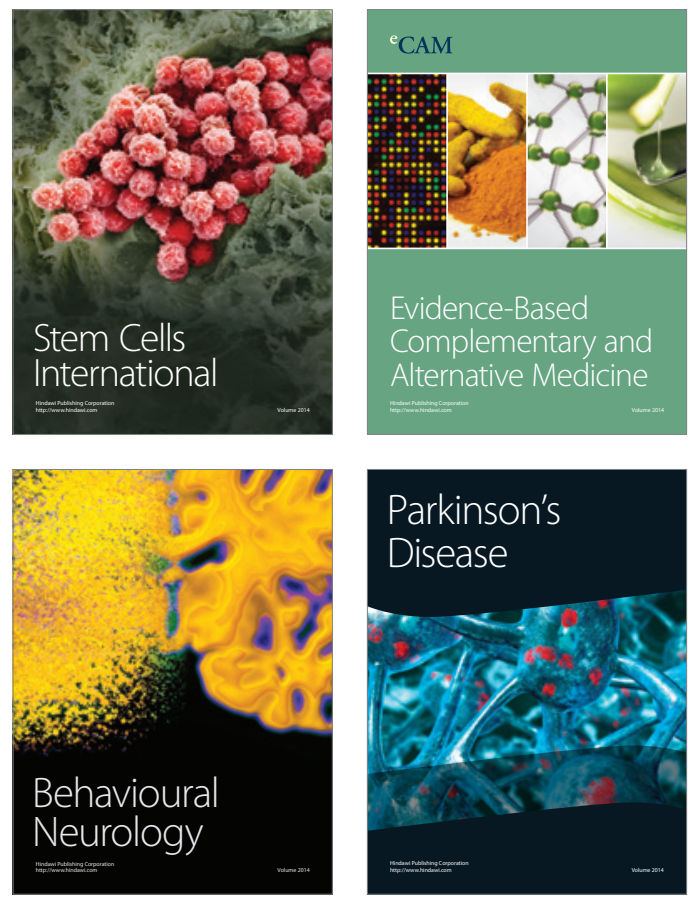
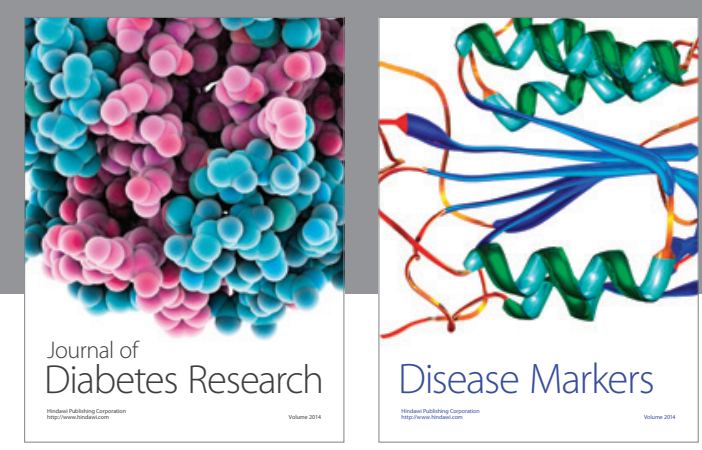

Disease Markers
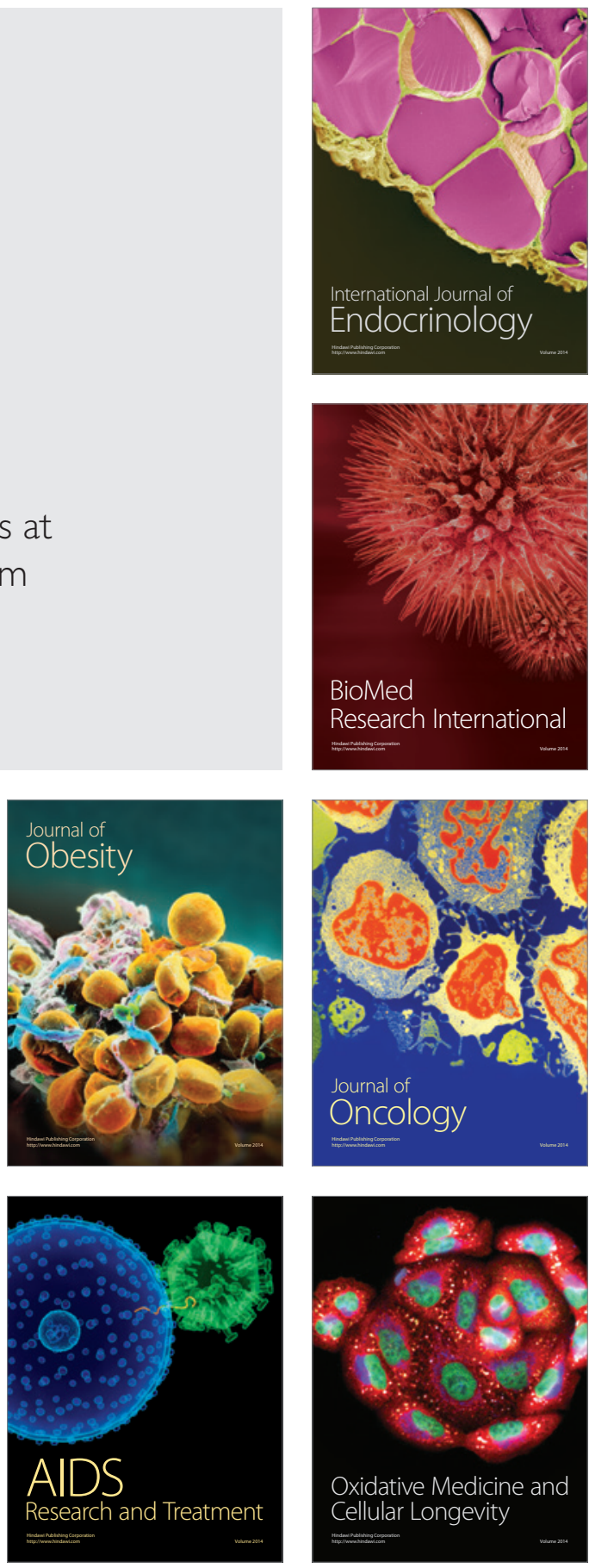